\title{
Harnessing Learners' Perceptual Load, the Attentional States, and Interactions in Digital Learning Environments
}

\author{
Indika Karunaratne \\ University of Colombo School of Computing \\ University of Colombo, Sri Lanka \\ indikak@uom.lk
}

\begin{abstract}
Learning effectiveness is highly subjective. It depends on how well an individual gets involved with learning: being attentive and engaged. It has been looked into from many different aspects: educational, psychological, and technological. Yet, we could not find appropriate mechanisms to perform an in-situ assessment of the attentional state of a learner. To address this deficiency, we initiate a blended approach that brings together the educational, psychological, and technological aspects related to attention in digital learning environments. We propose to predict the attentional state of a leaner by analyzing user interactions and the perceptual load presented by the learning activity. We suggest two ways to use these predictions: (1) Notify the user about wavering of attention so that the learner will be able to enhance his engagement with the learning activity (2) As an insight to the learning activity if many learners engaged with the activity find it difficult to focus on. This work is expected to make a positive impact by enhancing effectiveness in teaching and learning in digital learning environments.
\end{abstract}

Attention, Distracters, Digital Learning Environments, Human Computer Interaction

\section{INTRODUCTION}

Attention is the key to successful learning (Hanley et al., 2017). In line with the advancements in technologies and the proliferation of digital devices, learning has undergone a lot of changes. We witness diversified learning environments in addition to traditional classrooms including, computer-assisted classrooms, smart classrooms, eLearning, mobile learning, and massive open and online courses (MOOCs). Whether these environments are conducive for learners to direct and maintain attention in learning is still questionable. Excessive use of digital devices and media may cause a lot of distractions. According to research, too much exposure to digital media causes learners to multitask more (Foehr, 2003), causing fragmented attention which impacts negatively on learning.

This research intends to explore how technology itself can be used to reduce the negative impacts of technology on learning. We will investigate how technology can be used to identify the learners' attentional state at the time and to support enhancing attention of learners to make learning more effective.
Accordingly, following research questions have been formulated.

- RQ1: What are the most common distracters in a smart learning environment?

- RQ2: What is the nature of the relationship between the learners' susceptibility to distraction/ attentional states and the currently engaged learning activity?

- RQ3: How could technology be used to assess, intervene and enhance learners' attention to ensure better learning in a smart classroom environment?

In the next section, we provide a further insight into the background of the problem stated. In Section 3 the proposed approach is discussed in detail. Then we provide a summary of related work in Section 4, which will then be followed by the Conclusion section, we appraise the proposed approach and highlight the expected contributions. 


\section{BACKGROUND}

Recently, a lot of scholarly work has been carried out considering and revealing the effect of interruptions and multitasking in peoples' lives. Relevant studies were conducted in many areas including work and college (Czerwinski et al., 2004; lqbal and Horvitz, 2007; Mark et al., 2016a, 2014b; Züger and Fritz, 2015). It has also noted that more exposure to media implies high amount of multitasking (Foehr, 2003), task switching is common in computing-related work (Iqbal and Horvitz, 2007), and information work is highly fragmented (Czerwinski et al., 2004; González and Mark, 2004). When the peripheral tasks interrupt the primary task it requires more time to complete the primary task (Bailey and Konstan, 2006), more often they take significantly more time to return to and resume work (lqbal and Horvitz, 2007).

Based on an empirical study conducted focusing college students, Mark, Wang, and Niiya state that the amount of multitasking is positively associated with stress (Mark et al., 2014b). The stress is also identified as a cause for sleeping deficiencies, declining of positive affect, conversation and activity (Wang et al., 2014). Negative moods cause reduced attention (Mark et al., 2016c), while students with less sleep could become more distractible, both internally and externally. Smartphone overuse is another significant reason for attention deficits and sleep deprivations among college students (Lee et al., 2014). Smartphone notifications are known to be a great contributor to increasing inattention. It elicits and increases hyperactivity symptoms even in those who do not have Attention Deficit Hyperactivity Disorder (ADHD) (Kushlev et al., 2016). The excessive use of modern communication technologies, stress, sleeping deficiencies and attention-related problems seem to be interlinked, and impactful of one another. Constant switching is said to be habitual, and millennials are known to be multitasking more than adults. Specifically, multitasking frequency of college students is double compared to an information worker (Rodgers et al., 2016).

Higher multi-taskers are said to have shorter focus durations (Mark et al., 2016a, 2016c; Monk et al., 2004), providing further implications of the declining of attentional capacities, and learning performance of individuals. Even though some amount of multitasking does not have adverse effects on performance (Davidson, 2011), an intensive amount of multitasking causes poor performance (Adler and Benbunan-Fich, 2012, 2015).

\section{PROPOSED APPROACH}

The research will be conducted following exploratory design. It is expected to be conducted mainly in the smart classroom environment, choosing a sample from a student population aged between 18 to 25 years. The subjects are expected to have the necessary skills in the smart classroom setup.

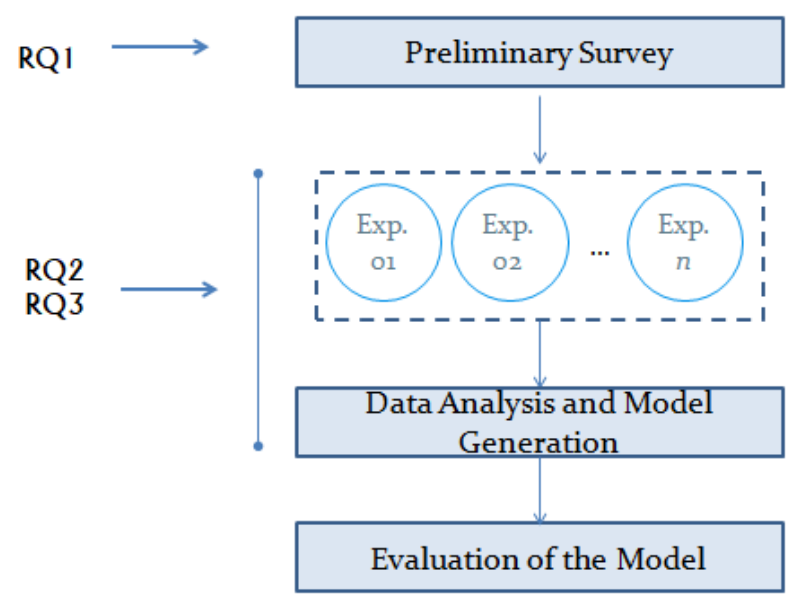

Figure 1: Overview of the Research Design

The overview of research design shown in Figure 1 provides an at-a-glance plan of how the research will be conducted. Also, it illustrates how research questions are addressed at different stages.

Each subject will complete one-time preliminary questionnaire-based survey which is used to evaluate the learners' awareness and causes of attentional state shifts, and associated interactions with attentional states. It is expected to answer the first research question (RQ1: What are the most common distracters in a smart learning environment?) through this survey. The questionnaire will consist of several sections to collect; (1) demographic information, (2) learning areas and learning methods preferences (3).awareness on attentional states, attention shifts, and distracters, (4) frequented interactions at different levels of challenges and engagements. The data will be used in establishing a prototype to the technological component to assist managing attentional state of learners.

Subjects will then engage in experiments consisting of learning sessions carefully planned with different levels of mental, physical, and temporal demands to induce their behavior at different levels challenges and perceptual loads. A series of experiments will be carried out to enable multiple subjects to be observed under the same experimental task and the same subject to be observed with a number of experimental tasks. The number of experiments is not predefined, but instead will be determined during the research execution time based on the nature of the experiment and its outcomes. However, it is expected to carry out a minimum of three 
experiments. The section 3.1 will discuss the design of an experiment in detail. The data collected during experiments will then be analyzed and a model will be developed to predict the attentional state of a learner based on the interactions and the perceptual load. The proposed architecture is discussed in detail in section 3.3. The series of experiments and the data analysis and model generation stage will collectively contribute to answering the research questions $R Q 2$ and $R Q 3$.

The generated model will be evaluated empirically. The process is further discussed in Section 3.4.

\subsection{Experimental Design}

Each experiment is constructed around a carefully planned and developed learning task. A short quiz will be given at the end of each learning task to evaluate learners' performance. The average perceptual load expected to be induced by each learning task is pre-defined. This will later be tallied with the actual perceptual load reported by the learner at the exit questionnaire. When the learner is engaged with the learning task, the learner interactions will be recorded. We consider two types of interactions; explicit, behavioral interactions and implicit psycho-physiological signals depicted in Figure 2 as Interaction Log and Psychophysiological readings respectively. The set of behavioral interactions parameters have been identified at the preliminary questionnaire survey. As the literature suggests a close relationship with psychological stress ad attentional states psychophysiological signals (ie. pulse rate, pupil dilation) are recorded mainly for the crossreferencing purposes. These interactions are recorded as unobtrusively as possible.

During the learning activities, planned distractions will be presented time to time with the objective of identifying the subject's vulnerability to distracters. These distractions will be carefully selected to induce both external and internal distractions in the subject.

At the end of each experiment session, subjects will be asked to fill out a questionnaire to evaluate the workload and the level of attention (ie. NASA Task Load Index/ questionnaire adapted from the framework of quadrants representing different attentional states).

Finally, these records will be analyzed to reveal correlations, which will then be used to estimate the imposed load of attention and perception by a learning activity on a learner, and support planning of learning activities which utilize learners' perceptual capacity in an optimal manner.

\subsection{Data Collection and Storage}

The data collected will be anonymous. Subjects will be given an identification code at the beginning, and the same code will be used through the series of experimental sessions. Correspondence will be maintained through the identification code only.

Interactions

Perceptual Load

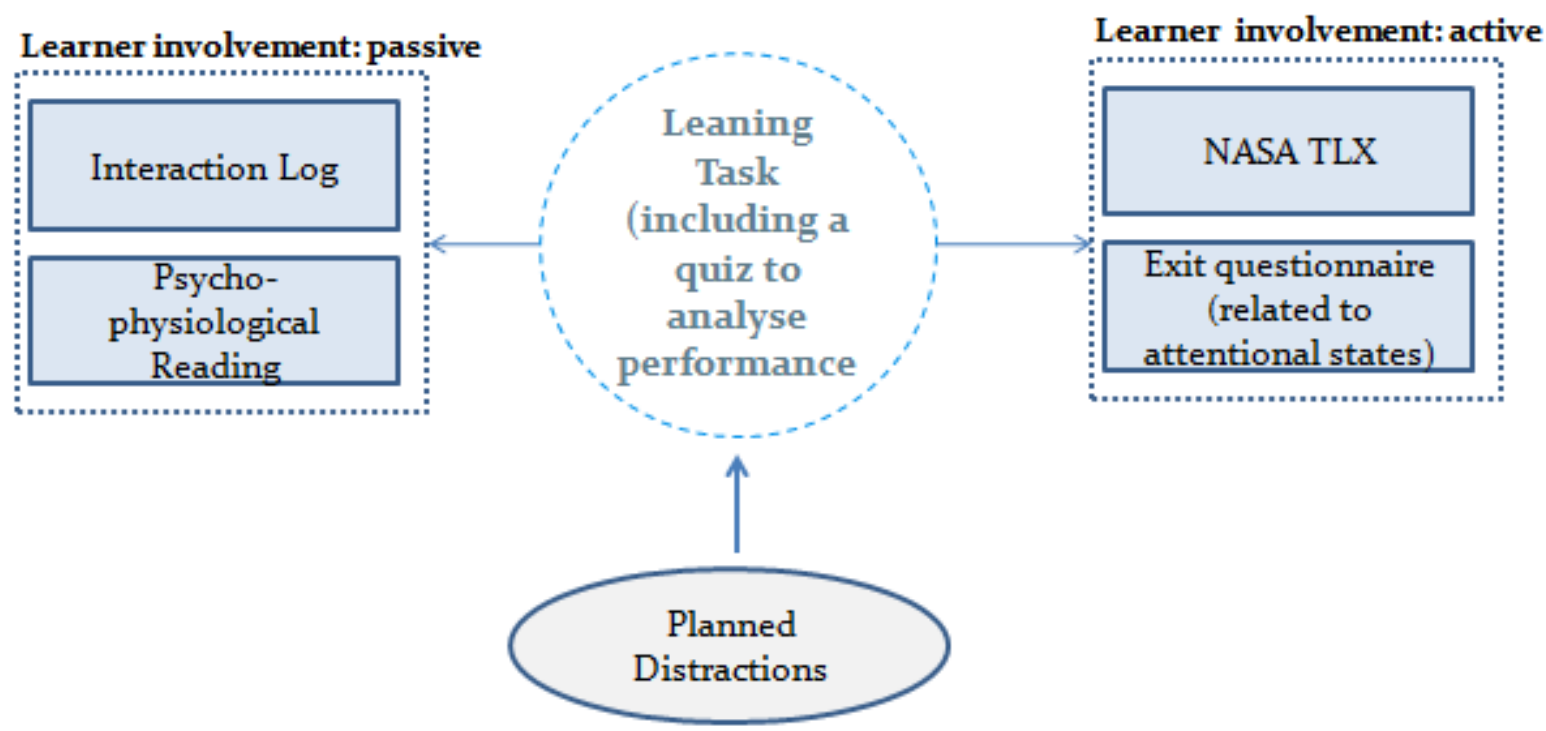

Figure 2: Experimental Design 


\subsection{Proposed System Architecture}

We consider the Mark et al.'s theoretical framework of quadrants representing different attentional states in the workplace (Mark et al., 2014a) and the Lavie's load theory of attention (Lavie et al., 2004; Kyndt et al., 2011). It is envisaged that the perceptual load presented by a task is synonymous with the challenge imposed by it. It is also assumed that the user interactions can be used to gauge the level of engagement.

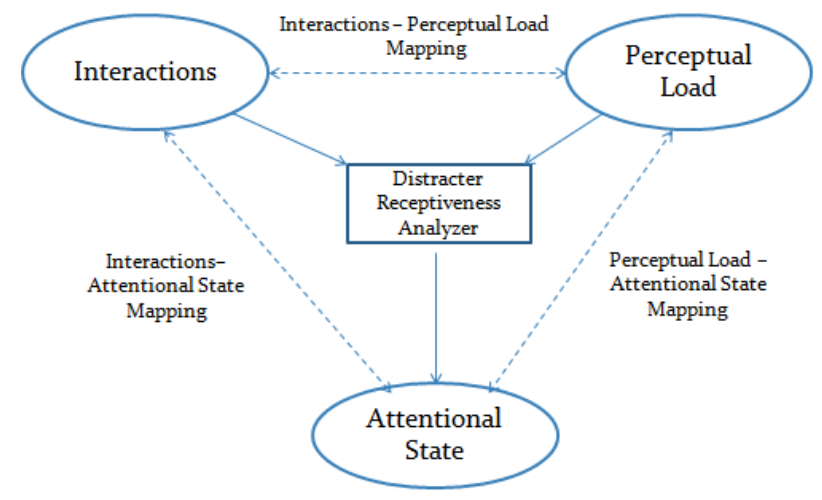

Figure 3: System Architecture

Accordingly, we propose a system (Figure 3) which brings together the perceptual load related to a learning activity, the attentional state of a learner, and his interactions. The distractor receptiveness analyzer will determine the attentional state of the learner by taking the determinants; interactions and the perceptual load into account.

\subsection{Evaluation of the Model}

Both the questionnaires (Preliminary survey and the exit questionnaire) planned in the research will be evaluated for the suitability through experts' review as a pre-test. The same will be post-tested for reliability using a standard reliability measure (i.e. Cronbach's alpha).

The most important and challenging component would be the evaluation of the model. The evaluation process will be empirically based and will highly rely on human judgments.

When the model suggests the attentional state of the learner during a learning activity, it will be tallied against,

- The learner's self-report

- The performance in the quiz associated with the learning activity

- Assessment by a facilitator through passive observation (more subjective)

\section{RELATED WORK}

\subsection{Effects and Impact of Interruptions and Multitasking}

Jo, Kim, and Seo have considered the effect of interruptions on a text reader highlighting the fact that the reader might find it difficult to resume the reading immediately after returning from the distraction. Scanning through the document and identifying where to start re-reading from costs time, effort, and interest. They presented the concept of gaze-based bookmarking to assist the reader to resume reading after being interrupted from a text reading task (Jo et al., 2015). In addition, the effect of chronic multitasking on analytical writing has also been identified as negative. The writing suffered from the increasing number of switching between tasks, both when multitasked to access relevant information and irrelevant information (Lottridge et al., 2015). Email checking habits of a person are also identified as influential on their productivity based on the nature and the intensity of interruption the email checking process induce on the task being attended at the time. If one decides to check emails based on the email notification as and when it arrives or check emails according to his own liking. The former is an external interruption, and the latter is an internal interruption (Mark et al., 2016b), causing external divided attention and internal divided attention respectively.

\subsection{Technological Interventions in Capturing and Maintaining Attention}

Xiao and Wang proposed OneMind to detect the presence, type and the intensity of into attention of learners in MOOC learning environments. OneMind adopts tangible video control interface to manipulate video lessons, using back camera of a mobile phone as the play button of the learning video. Covering the camera using the finger elicit 'play' command whereas uncovering elicits the pause 'command'. Commodity camera based PPG sensing was used to monitor pulse rate of the user, as a physiological measure related to the situation. Xiao and Wang reveal that internal divided attention has a significant negative impact on learning in MOOC learning environments, and it is reflected in students' learning outcomes. They propose to switch to less-attention-demanding activities when the consistent divided attention is detected (Xiao and Wang, 2017).

\subsection{The Task: Load, Challenge, Engagement, and Attention}

Attentional state of an information worker may change due to various reasons such as the task at 
hand, Interactions and affective state of the user. It may also get affected by interruptions and other contextual conditions. Those who are engaged in digital activities may multitask frequently, and these digital activities may cause fragmented attention, and thereby the negatively affect the engagement in the work (Mark et al., 2016a).

The theoretical framework (shown in Figure 4) proposed by Mark et.al. presents four different attentional states based on the challenge of work and engagement with work. This could be used to assess engagement and challenge in work activities. The quadrants of the framework give an insight to the expected changes in attention when the level of engagement and the challenge of task changes. For the worker to focus on the task, it needs to present him with enough challenge, while providing ample opportunities to get engaged with it. The tasks which solicit engagement but does not have sufficient amount of challenge fail to capture attention (Mark et al., 2014a) and therefore the worker become more susceptible to distractions.

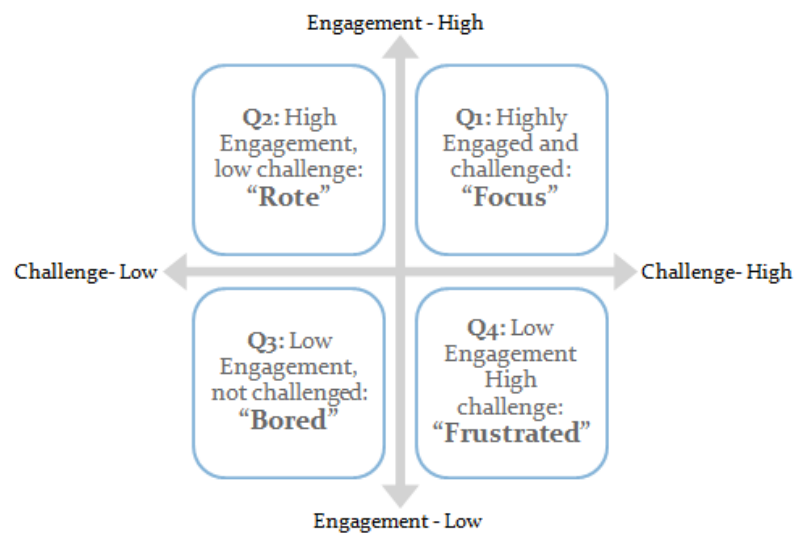

Figure 4: A theoretical framework of quadrants representing different attentional states in the workplace (Mark et al., 2014a)

Load theory of attention and perception provides a complimentary insight but goes deeper into the attention capacity of an individual. According to load theory, the attention capacity of an individual is fixed, and when multitasking occurs the attention is divided between the tasks. Its key argument is that if the task at hand presents enough perceptual load to fill the attention capacity, the receptiveness for distraction is reduced (Forster and Lavie, 2009; Lavie et al., 2004). Distracter can be internal or external, and also task-relevant or task-irrelevant. Current task's perceptual load determines whether to accept or reject the task-irrelevant distracter (Forster, 2013; Lavie et al., 2014). This emphasizes the importance of task-load assessment if required to capture and keep attention. NASA- Task Load Index (NASA-TLX) assesses the overall workload ("NASA Task Load Index (TLX)," n.d.), and has been tested in many disciplines including health and students in schools and colleges (Laurie-Rose et al., 2014; Tubbs-Cooley et al., 2018).

\section{CONCLUSION}

Measuring and maintaining attention related to the load theory of attention and perception is quite an under-researched area, especially in the human computer interaction discipline. Thus the research is expected to make contributions to open up new avenues in research. It will also enhance learning experience and performance of learners in smart classrooms while providing better insights to instructional designers in developing learning activities.

In particular, it is expected to develop a computational model harnessing the load theory of attention and the theoretical framework of quadrants of attentional states. The model will be comprised of a background interaction capturing module, mapping tool for background interaction data and the physiological measures, and data analysis algorithms. These contributions are expected to be used and explored in future research and developments in the fields of $\mathrm{HCl}$, Education, and Psychology.

\section{ACKNOWLEDGEMENT}

The supervisor of this work is Dr. Ajantha Atukorale at the University of Colombo School of Computing, and his support and guidance are gratefully acknowledged.

\section{REFERENCES}

Adler, R.F., Benbunan-Fich, R., 2015. The Effects of Task Difficulty and Multitasking on Performance. Interact. Comput. 27, 430-439. https://doi.org/10.1093/iwc/iwu005

Adler, R.F., Benbunan-Fich, R., 2012. Juggling on a high wire: Multitasking effects on performance. Int. J. Hum.-Comput. Stud. 70, 156-168. https://doi.org/10.1016/j.ijhcs.2011.10.003

Bailey, B.P., Konstan, J.A., 2006. On the need for attention-aware systems: Measuring effects of interruption on task performance, error rate, and affective state. Comput. Hum. Behav. 22, 685708. https://doi.org/10.1016/j.chb.2005.12.009

Czerwinski, M., Horvitz, E., Wilhite, S., 2004. A diary study of task switching and interruptions. ACM Press, pp. 175-182. https://doi.org/10.1145/985692.985715

Davidson, C.N., 2011. Now you see it: how the brain science of attention will transform the way we live, work, and learn. Viking, New York. 
Foehr, U.G., 2003. Media Multitasking among American Youth: Prevalence, Predictors and Pairings (Unpublished PhD Thesis). Stanford, CA, USA.

Forster, S., 2013. Distraction and Mind-Wandering Under Load. Front. Psychol. 4. https://doi.org/10.3389/fpsyg.2013.00283

Forster, S., Lavie, N., 2009. Harnessing the wandering mind: The role of perceptual load. Cognition 111, 345-355. https://doi.org/10.1016/j.cognition.2009.02.006

González, V.M., Mark, G., 2004. "Constant, constant, multi-tasking craziness": managing multiple working spheres. ACM Press, pp. 113120. https://doi.org/10.1145/985692.985707

Hanley, M., Khairat, M., Taylor, K., Wilson, R., Cole-Fletcher, R., Riby, D.M., 2017. Classroom displays-Attraction or distraction? Evidence of impact on attention and learning from children with and without autism. Dev. Psychol. 53, 1265-1275. https://doi.org/10.1037/dev0000271

lqbal, S.T., Horvitz, E., 2007. Disruption and recovery of computing tasks: field study, analysis, and directions. ACM Press, p. 677. https://doi.org/10.1145/1240624.1240730

James, W., 1995. The principles of psychology: in two volumes. Vol. 1: ..., Dover-books on biology, psychology and medicine. Dover, New York.

Jo, J., Kim, B., Seo, J., 2015. EyeBookmark: Assisting Recovery from Interruption during Reading. ACM Press, pp. 2963-2966. https://doi.org/10.1145/2702123.2702340

Kushlev, K., Proulx, J., Dunn, E.W., 2016. "Silence Your Phones": Smartphone Notifications Increase Inattention and Hyperactivity Symptoms. ACM Press, pp. 1011-1020. https://doi.org/10.1145/2858036.2858359

Kyndt, E., Dochy, F., Struyven, K., Cascallar, E., 2011. The perception of workload and task complexity and its influence on students' approaches to learning: a study in higher education. Eur. J. Psychol. Educ. 26, 393-415. https://doi.org/10.1007/s10212-010-0053-2

Laurie-Rose, C., Frey, M., Ennis, A., Zamary, A., 2014. Measuring perceived mental workload in children. Am. J. Psychol. 127, 107-125.

Lavie, N., Beck, D.M., Konstantinou, N., 2014. Blinded by the load: attention, awareness and the role of perceptual load. Philos. Trans. R. Soc. B Biol. Sci. 369, 20130205-20130205. https://doi.org/10.1098/rstb.2013.0205

Lavie, N., Hirst, A., de Fockert, J.W., Viding, E., 2004. Load Theory of Selective Attention and Cognitive Control. J. Exp. Psychol. Gen. 133,
339-354.

3445.133.3.339

Lee, U., Song, J., Lee, J., Ko, M., Lee, C., Kim, Y., Yang, S., Yatani, K., Gweon, G., Chung, K.-M., 2014. Hooked on smartphones: an exploratory study on smartphone overuse among college students. ACM Press, pp. 2327-2336. https://doi.org/10.1145/2556288.2557366

Lottridge, D.M., Rosakranse, C., Oh, C.S., Westwood, S.J., Baldoni, K.A., Mann, A.S., Nass, C.I., 2015. The Effects of Chronic Multitasking on Analytical Writing. ACM Press, pp. 2967-2970. https://doi.org/10.1145/2702123.2702367

Mark, G., lqbal, S.T., Czerwinski, M., Johns, P., 2014a. Bored mondays and focused afternoons: the rhythm of attention and online activity in the workplace. ACM Press, pp. 3025-3034. https://doi.org/10.1145/2556288.2557204

Mark, G., lqbal, S.T., Czerwinski, M., Johns, P., Sano, A., 2016a. Neurotics Can't Focus: An in situ Study of Online Multitasking in the Workplace. Presented at the $\mathrm{CHI} 2016$, ACM Press, pp. 1739-1744. https://doi.org/10.1145/2858036.2858202

Mark, G., lqbal, S.T., Czerwinski, M., Johns, P., Sano, A., Lutchyn, Y., 2016b. Email Duration, Batching and Self-interruption: Patterns of Email Use on Productivity and Stress. ACM Press, pp. 1717-1728.

https://doi.org/10.1145/2858036.2858262

Mark, G., Wang, Y., Niiya, M., 2014b. Stress and multitasking in everyday college life: an empirical study of online activity. Presented at the $\mathrm{CHI}$ 2014, ACM Press, pp. 41-50. https://doi.org/10.1145/2556288.2557361

Mark, G., Wang, Y., Nliya, M., Reich, S., 2016c. Sleep Debt in Student Life: Online Attention Focus, Facebook, and Mood. Presented at the CHI 2016, San Jose, CA, USA, pp. 5517-5528.

Monk, T.H., Buysse, D.J., Potts, J.M., DeGrazia, J.M., Kupfer, D.J., 2004. MorningnessEveningness and Lifestyle Regularity. Chronobiol. Int. 21, 435-443. https://doi.org/10.1081/CBI-120038614

NASA Task Load Index (TLX), n.d.

Rodgers, S., Maloney, B., Ploderer, B., Brereton, M., 2016. Managing Stress, Sleep and Technologies: An Exploratory Study of Australian University Students. Presented at the $\mathrm{ozCHI}$, Launceton, TAS, Australia.

Tubbs-Cooley, H.L., Mara, C.A., Carle, A.C., Gurses, A.P., 2018. The NASA Task Load Index as a measure of overall workload among neonatal, paediatric and adult intensive care 
nurses. Intensive Crit. Care Nurs. https://doi.org/10.1016/j.iccn.2018.01.004

Wang, R., Chen, F., Chen, Z., Li, T., Harari, G., Tignor, S., Zhou, X., Ben-Zeev, D., Campbell, A.T., 2014. StudentLife: assessing mental health, academic performance and behavioral trends of college students using smartphones. ACM Press, pp. 3-14. https://doi.org/10.1145/2632048.2632054

Xiao, X., Wang, J., 2017. Undertanding and Detecting Divided Attention in Mobile MOOC Learning. ACM Press, pp. 2411-2415. https://doi.org/10.1145/3025453.3025552

Züger, M., Fritz, T., 2015. Interruptibility of Software Developers and its Prediction Using PsychoPhysiological Sensors. ACM Press, pp. 29812990. https://doi.org/10.1145/2702123.2702593 